\title{
VARIABILIDADE ESPACIAL DA DENSIDADE E DA POROSIDADE DE UM LATOSSOLO VERMELHO EUTROFÉRRICO SOB SEMEADURA DIRETA POR VINTE ANOS $\left({ }^{1}\right)$
}

\author{
GLÉCIO MACHADO SIQUEIRA $\left({ }^{2 *}\right)$; SIDNEY ROSA VIEIRA $\left({ }^{3}\right)$; \\ SONIA CARMELA FALCI DECHEN $\left({ }^{3}\right)$
}

\begin{abstract}
RESUMO
Todas as práticas de manejo causam impacto sobre os atributos do solo que se traduzem em influência sobre o desenvolvimento das culturas. Sabe-se que no sistema de semeadura direta ocorre compactação do solo na camada superficial, com tendência a progredir com o tempo de cultivo. Este trabalho teve como objetivo avaliar a variabilidade espacial da densidade e da porosidade de um Latossolo Vermelho eutroférrico sob semeadura direta por vinte anos. O trabalho foi desenvolvido em Campinas (SP) considerando o período entre 1985 e 2005. Os atributos analisados neste estudo foram: argila $\left(\mathrm{g} \mathrm{kg}^{-1}\right)$, silte $\left(\mathrm{g} \mathrm{kg}^{-1}\right)$, areia $\left(\mathrm{g} \mathrm{kg}^{-1}\right)$, densidade $\left(\mathrm{kg} \mathrm{dm}^{-3}\right)$, porosidade total $(\%)$, macroporosidade $(\%)$ e microporosidade $(\%)$. Ferramentas de geoestatística foram utilizadas para análise dos dados e construção de mapas de variabilidade espacial da densidade e da porosidade do solo. A amostragem realizada em 1985 não foi capaz de detectar a variabilidade espacial da densidade e porosidade do solo. Nos atributos físicos amostrados em 2005, observou-se alta razão de dependência espacial. Nos mapas de variabilidade espacial não se constatou relação clara entre a textura, a densidade e a porosidade do solo. Na área após vinte anos de manejo com semeadura direta não havia problemas com compactação. O manejo do solo com semeadura direta influenciou favoravelmente a variabilidade espacial dos atributos amostrados em 2005.
\end{abstract}

Palavras-chave: atributos físicos do solo, manejo do solo, geoestatística.

\section{ABSTRACT \\ SPATIAL VARIABILITY OF SOIL BULK DENSITY AND SOIL POROSITY ON A RHODIC EUTRUDOX UNDER NO TILLAGE FOR TWENTY YEARS}

Soil management practices affect its attributes which will further affect crop development. It is generally known and accepted that soil surface compaction occurs in no tillage system and that this compaction tends to increase with time. However, most of the research do not evaluate adequately soil physical properties behavior as affected by time of management. The objective of this work was to evaluate spatial variability of soil bulk density and soil porosity on a Rhodic Eutrudox under no tillage with annual crops for twenty years. The work was conducted in Campinas, São Paulo State, considering the period between 1985 and 2005. The attributes analyzed in this study were: clay $\left(\mathrm{g} \mathrm{kg}^{-1}\right)$, silt $\left(\mathrm{g} \mathrm{kg}^{-1}\right)$, sand $\left(\mathrm{g} \mathrm{kg}^{-1}\right)$, soil bulk density $\left(\mathrm{kg} \mathrm{dm}^{-3}\right)$, soil porosity $(\%)$, macroporosity (\%) and microporosity (\%). Geostatistics was used to analyze the data and the spatial variability maps of compaction and porosity of soil attributes. The sampling conducted in 1985 was unable to detect the spatial variability of density and porosity of the soil. The physical attributes sampled in 2005 showed large ratio of spatial dependence. The maps of spatial variability did not show a clear link between the texture, soil bulk density and soil porosity. After 20 years no tillage management the area did not present problems of compaction. No tillage influenced favorably the spatial variability of soil attributes sampled in 2005.

Key words: soil physical attributes, soil management, geostatistics.

( $\left.{ }^{1}\right)$ Parte da Dissertação de Mestrado em Agricultura Tropical e Subtropical (IAC) do primeiro autor. Recebido para publicação em 23 de janeiro de 2006 e aceito em 20 de março de 2009.

$\left({ }^{2}\right)$ Doutorando em Engenharia para o Desenvolvimento Rural, Universidade de Santiago de Compostela (USC), Campus Universitario, 27002 Lugo, Espanha. E-mail: glecio.machado@rai.usc.es $\left(^{*}\right)$ Autor correspondente. Bolsista MAEC-AECI.

$\left({ }^{3}\right)$ Instituto Agronômico (IAC), Centro de Pesquisa e Desenvolvimento de Solos e Recursos Ambientais, Caixa Postal 28, 13020-902 Campinas (SP). E-mail: sidney@iac.sp.gov.br; dechen@iac.sp.gov.br 


\section{INTRODUÇÃO}

Os sistemas conservacionistas de preparo do solo, como o sistema de semeadura direta visam à produção agrícola sustentável com o mínimo revolvimento do solo. Desta maneira, no sistema de semeadura direta, o solo não é revolvido, conservando os resíduos vegetais na sua superfície, o que favorece o aumento do teor de matéria orgânica (BERTOL et al., 2001, AMADO et al., 2005); e por outra parte, o nãorevolvimento do solo contribui para o aumento da densidade nas camadas iniciais do solo, com redução da porosidade superficial (BEUTLER et al., 2001).

Os atributos físicos do solo desempenham importante papel, senão o principal, dentre as propriedades do solo (WARRICK e Nielsen, 1980). Assim, o sistema de semeadura direta proporciona, na camada superficial, valores mais elevados de densidade e microporosidade, e menores valores de macroporosidade, quando comparado com o plantio convencional (BEUTLER et al., 2001; SPERA et al., 2004). Esse fato decorre principalmente do arranjamento natural do solo quando não é revolvido e da pressão provocada pelo trânsito de máquinas e implementos agrícolas, sobretudo quando realizado em solos argilosos e com teores elevados de umidade (STONE e Silveira, 2001).

Sabe-se que a compactação do solo age sobre o desenvolvimento das culturas, restringindo o crescimento radicular e consequentemente diminuindo o volume de solo explorado pelas raízes (FolONI et al., 2003). Verifica-se, também, no sistema de semeadura direta, que há maior estabilidade dos agregados e maior continuidade dos poros favorecendo a infiltração de água e dificultando o escorrimento superficial, quando comparado com o preparo convencional (ShIPITALO e Protz, 1987; KLEPKER e ANGHINONI, 1995).

De acordo com Grego e Vieira (2005), o conhecimento da variabilidade espacial dos atributos do solo e das culturas, no espaço e no tempo, é considerado, atualmente, como o princípio básico para o manejo preciso das áreas agrícolas, qualquer que seja sua escala. CorÁ et al. (2004) e REICHARDT e TIMM (2004) descrevem que o manejo do solo propicia alterações na variabilidade natural do solo, principalmente nas camadas superficiais. Desta maneira, a geoestatística tem sido usada com bastante sucesso em estudos de física do solo, pois se baseia em uma função aleatória contínua estacionária, a qual pode ser submetida a uma grande gama de hipóteses (SIQUeIRA et al., 2008). $\mathrm{Na}$ prática, a existência de estacionalidade dá a oportunidade de repetir um experimento mesmo que as amostras devam ser coletadas em pontos diferentes, porque todas são consideradas pertencentes à mesma população e com os mesmos momentos estatísticos (VIEIRA, 2000).

Assim, o conhecimento da variabilidade espacial dos atributos físicos do solo ao longo do tempo contribui para a aplicação de manejo adequado ao solo, possibilitando conhecer o comportamento dos atributos do solo influenciados pelo manejo do solo e, propiciando a determinação de zonas que necessitem de manejo diferenciado. Dessa maneira, o presente trabalho teve como objetivo avaliar a variabilidade espacial da densidade e da porosidade de um Latossolo Vermelho eutroférrico sob semeadura direta por vinte anos.

\section{MATERIAL E MÉTODOS}

O experimento foi realizado em Campinas (SP). As coordenadas geográficas da área são latitude $22^{\circ} 53^{\prime}$ Sul e longitude $47^{\circ} 04^{\prime}$ Oeste, com altitude média de $600 \mathrm{~m}$ e declividade de cerca de $6,5 \%$.

O clima da região é do tipo Cwa, segundo classificação climática de Köppen, com uma precipitação pluvial média anual de $1.382 \mathrm{~mm}$ (Ortolani et al., 1995). O solo da área é de Latossolo Vermelho eutroférrico, de textura argilosa (EMBRAPA, 1999), correspondente ao Rhodic Eutrudox (USDA, 1996) ou Rhodic Ferralsol (FAO, 1994).

Este estudo foi desenvolvido na área de um experimento de longa duração instalado desde 1985, em 3,42 hectares, sob o sistema de semeadura direta. A área foi mantida sem nenhum cultivo de 1975 a 1985. Em março de 1985 o campo foi inteiramente limpo, arado e cultivado com Crotalaria juncea L. e, em novembro do mesmo ano, o campo foi subsolado, calcariado, arado, gradeado e cultivado com soja. Desde então, o sistema adotado é o de semeadura direta com soja [Glicine max (L.) Merrill] e milho (Zea mays L.) em anos alternados no verão e aveia preta (Avena strigosa Schieb.), centeio (Cecale cereale L.), triticale (Triticale secale L.), trigo (Triticum aestivum L.) ou Crotalaria juncea L. como culturas de inverno.

As amostras foram coletadas na camada de 0 a $10 \mathrm{~cm}$, com anéis volumétricos de $100 \mathrm{~cm}^{3}$, em março de 1985 em 63 pontos de amostragem com espaçamento regular de $20 \mathrm{~m} \times 20 \mathrm{~m}$ e em janeiro de 2005 em 302 pontos de amostragem com espaçamento regular de $10 \mathrm{~m}$ x $10 \mathrm{~m}$ (Figura 1). Em 1985 foram avaliados os seguintes atributos físicos do solo: textura $\left(\mathrm{g} \mathrm{kg}^{-1}\right)$, densidade $\left(\mathrm{kg} \mathrm{dm}^{-3}\right)$, porosidade total $\left(\mathrm{m}^{3} \mathrm{~m}^{-3}\right)$, macroporosidade $\left(\mathrm{m}^{3} \mathrm{~m}^{-3}\right)$ e microporosidade $\left(\mathrm{m}^{3} \mathrm{~m}^{-3}\right)$. Em 2005 foram avaliados: densidade $\left(\mathrm{kg} \mathrm{dm}^{-3}\right)$, porosidade total $\left(\mathrm{m}^{3} \mathrm{~m}^{-3}\right)$, macroporosidade $\left(\mathrm{m}^{3} \mathrm{~m}^{-3}\right)$, microporosidade $\left(\mathrm{m}^{3} \mathrm{~m}^{-3}\right)$. Todos os atributos físicos estudados foram analisados de acordo com metodologia proposta por CAMARGO et al. (1986). 


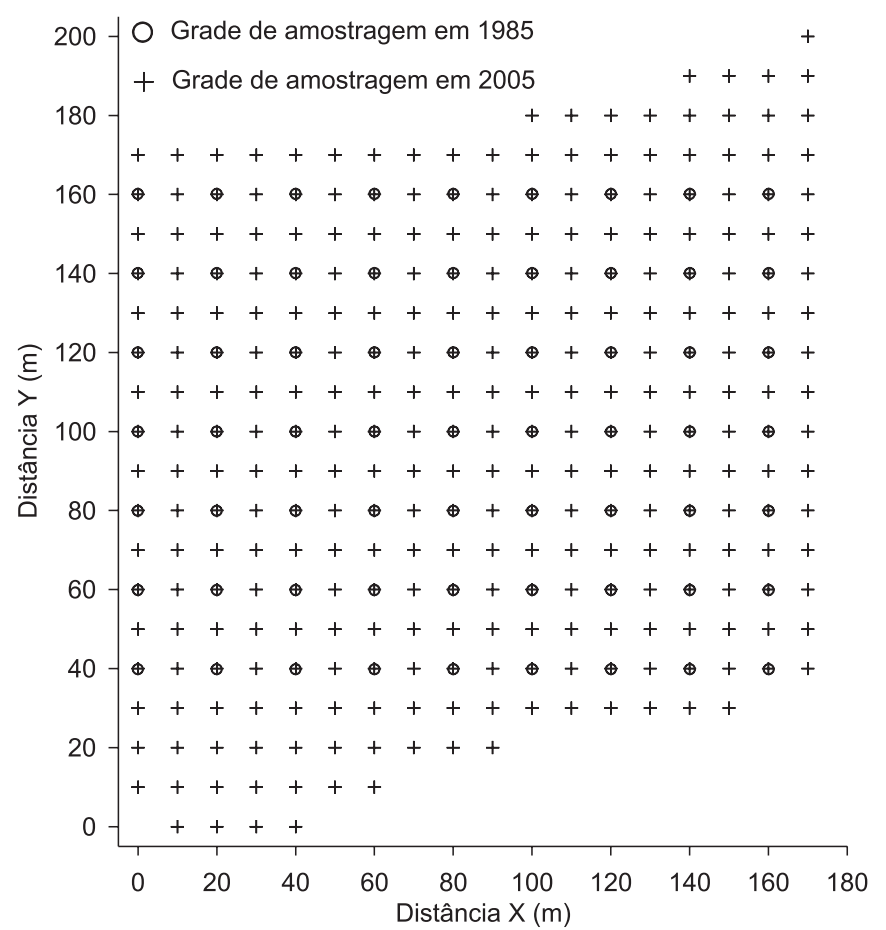

Figura 1. Grade de amostragem para a área de estudo em 1985 (63 pontos) e em 2005 (302 pontos).

A textura (argila, silte e areia) expressa neste estudo em $\mathrm{g} \mathrm{kg}^{-1}$ foi determinada por meio do método da pipeta, utilizando a fração do solo menor que 2 mm (TFSA), empregando como dispersante químico o hidróxido de $\mathrm{Na}$ e hexametafosfato de $\mathrm{Na}$.

Os dados de densidade do solo $\left(\mathrm{kg} \mathrm{dm}^{-3}\right)$ foram obtidos utilizando anéis volumétricos de 100 $\mathrm{cm}^{3}$, e em laboratório a densidade do solo foi determinada pela relação massa de solo por unidade de volume.

A porosidade total do solo $\left(\mathrm{m}^{3} \mathrm{~m}^{-3}\right)$ foi determinada pela diferença entre a massa da amostra saturada (Mssat, g) e a massa da amostra seca (Mssec, g) em estufa a $105{ }^{\circ} \mathrm{C}$ por 24 horas, em relação ao volume do anel $\left(V, \mathrm{~cm}^{3}\right)$, conforme Equação 1:

$$
P T=\frac{M S s a t-M S \text { sec }}{V} 100
$$

A microporosidade do solo foi obtida em mesa de tensão com sucção correspondente a $60 \mathrm{~cm}$ de coluna de água $(6 \mathrm{kPa})$ por 24 horas garantindo assim a drenagem da água dos macroporos (poros com diâmetro $=0,05 \mathrm{~mm})$; a macroporosidade $\left(\mathrm{m}^{3} \mathrm{~m}^{-3}\right)$ foi determinada pela diferença entre a porosidade total e a microporosidade do solo.

Os valores de porosidade do solo (porosidade total, macroporosidade e microporosidade) são medidas adimensionais, e comumente expressas em porcentagem $(\%)$, a unidade usada neste trabalho.
Os dados foram analisados com o auxilio do programa STAT (VIEIRA et al., 2002), que forneceu os principais momentos estatísticos (valor mínimo e máximo, média, desvio padrão, coeficiente de variação, assimetria e curtose). Para determinar a presença de valores extremos (outliers) para o conjunto de dados, os mesmos foram analisados de acordo com a equação proposta por CAHN et al. (1994) (Equação 2):

$$
V e=\bar{X} \pm 4 \sigma
$$

onde: Ve representa os valores extremos mínimo e máximo; $X$ é média; ó é o desvio-padrão.

Ferramentas de geoestatística foram utilizadas para analisar a dependência espacial entre as amostras e para geração de mapas de isolinhas, utilizando o conjunto de programas GEOSTAT (VIEIRA et al., 2002). Uma vez detectada a variabilidade espacial entre amostras, o semivariograma foi ajustado aos seguintes parâmetros: efeito pepita $\left(\mathrm{C}_{0}\right)$; variância estrutural $\left(C_{1}\right)$ e alcance (a). A razão de dependência espacial ( $R D, \%)$ entre amostras foi determinada conforme descrito por CAMBARDELLA et al. (1994), sendo baixa $(75-100 \%)$, média (25-75\%) e alta $(0-25 \%)$ :

$$
R D=\left(\frac{C_{0}}{C_{0}+C_{1}}\right) * 100
$$

O semivariograma foi utilizado para determinar a variabilidade e dependência espacial das amostras para os diferentes atributos, conforme VIEIRA (2000). A técnica de interpolação por krigagem foi utilizada para determinar os valores dos locais não amostrados, buscando uma estimação linear (Equação 4), sem tendência (Equação 5) e com variância mínima (Equação 6) considerando os valores da análise espacial determinada por meio do semivariograma experimental.

$$
\begin{aligned}
& Z^{*}=\sum_{i=1}^{n} \lambda_{i} Z_{i} \\
& E\left(Z^{*}\right)=E(Z) \text { que é equivalente a } \sum_{i=1}^{n} \lambda_{i}=1 \\
& E\left[\left(Z^{*}-Z\right)^{2}\right]
\end{aligned}
$$

O programa SURFER (1999) foi utilizado para construção dos mapas de isolinhas para os atributos físicos do solo envolvidos neste estudo. Desta maneira, os parâmetros de ajuste do semivariograma foram utilizados no processo de construção dos mapas de isolinhas dos atributos com variabilidade espacial. Para efeito de comparação entre as distintas datas de amostragem, para os atributos sem variabilidade espacial, os mapas de isolinhas foram construídos utilizando os parâmetros de "default" do programa SURFER (1999), que se baseia em um modelo de interpolação linear por krigagem. 


\section{RESULTADOS E DISCUSSÃO}

Na tabela 1, estão relacionados os principais parâmetros estatísticos para os atributos físicos analisados. No teor de argila, na densidade do solo, porosidade total e microporosidade em 1985, juntamente com densidade e a porosidade total em 2005 observaram-se baixos valores de coeficiente de variação $(\mathrm{CV})$, de acordo com a classificação proposta por Gomes (1984). Para os teores de silte e areia em 1985 e a microporosidade em 2005 os valores de CV foram medianos. A macroporosidade em ambas as amostragem foi de alto valor de CV. Os valores de CV descritos neste estudo coincidem com os constatados por CARVAlHo et al. (2003) e Souza et al. (2004).

As análises dos coeficientes de assimetria e curtose permitem identificar se o conjunto de dados indica distribuição normal ou não. WeBSTER (2001) afirma que valores de assimetria até 0,5 indicam distribuição normal. Neste caso, então, para os dados de 1985 apenas a argila, silte e areia não indicavam distribuição normal, e, para os dados de 2005 apenas a microporosidade não revelou distribuição normal para o conjunto de dados analisados.

A verificação de distribuição normal ou nãonormal dos dados permite averiguar se existem valores extremos (outlier máximo e outlier mínimo) que destoam do conjunto de dados, possibilitando dessa maneira a exclusão de valores discrepantes que podem ser decorrentes de erros de amostragem ou de erros analíticos. A comparação entre os valores mínimo e máximo obtidos na amostragem e os valores extremos apresentados na tabela 1 demonstra que apenas o teor de silte (1985) e a microporosidade (2005) indicam valores extremos (outlier máximo). A análise dos dados de silte (1985) e de microporosidade (2005) demonstrou que existe um único valor extremo máximo em ambos os casos, ou seja, cerca de $1,58 \%$ (silte) e $0,33 \%$ (microporosidade) dos dados que não contribuíram individualmente para que a distribuição de frequência não seja normal e, portanto, não interferindo no processo de análise geoestatística.

Os parâmetros de ajuste do semivariograma são apresentados na tabela 2. Verifica-se que os atributos amostrados em 1985 revelaram efeito pepita puro, com exceção dos parâmetros texturais do solo (argila, silte e areia). A presença de efeito pepita puro para os atributos físicos do solo em 1985 (densidade, porosidade total, macroporosidade e microporosidade), indica que o espaçamento utilizado de $20 \mathrm{~m} \times 20 \mathrm{~m}$ não foi suficiente para detectar a variabilidade espacial destes atributos. Por outra parte, verifica-se que os atributos físicos do solo com variabilidade espacial se ajustaram ao modelo matemático esférico (Tabela 2), corroborando com outros autores que descrevem este modelo como o que mais se ajusta aos atributos de solo e planta (TRANGMAR et al., 1985; SOUZA et al., 1997; BERTOLANI e VIEIRA, 2001).

Os atributos texturais do solo (argila, silte e areia) indicaram média razão de dependência espacial. Para os atributos amostrados em 2005 a razão de dependência espacial foi alta (0-25\%) (Tabela 2), concordando com SOUZA et al. (2004) e Grego e VIEIRA (2005).

Tabela 1. Parâmetros estatísticos dos atributos físicos analisados em 1985 e 2005.

\begin{tabular}{|c|c|c|c|c|c|c|c|c|c|}
\hline \multirow{2}{*}{ Atributo } & \multicolumn{2}{|c|}{ Valor } & \multirow{2}{*}{ Média } & \multirow{2}{*}{ DP } & \multirow{2}{*}{$\mathrm{CV}(\%)$} & \multirow{2}{*}{ Assimetria } & \multirow{2}{*}{ Curtose } & \multicolumn{2}{|c|}{ Outlier } \\
\hline & Máximo & Mínimo & & & & & & Máximo & Mínimo \\
\hline & & & & 1985 & & & & & \\
\hline Argila, $\mathrm{g} \mathrm{kg}^{-1}$ & 0,64 & 0,49 & 0,58 & 2,99 & 5,12 & $-0,86$ & 0,84 & 0,70 & 0,46 \\
\hline Silte, $\mathrm{g} \mathrm{kg}^{-1}$ & 0,18 & 0,08 & 0,10 & 1,85 & 18,12 & 1,28 & 3,68 & 0,17 & 0,02 \\
\hline Areia, $\mathrm{g} \mathrm{kg}^{-1}$ & 0,47 & 0,19 & 0,31 & 4,01 & 12,63 & 1,24 & 5,34 & 0,47 & 0,15 \\
\hline Densidade, $\mathrm{kg} \mathrm{dm}^{-3}$ & 1,43 & 0,94 & 1,19 & 0,11 & 9,90 & 0,02 & $-0,45$ & 1,66 & 0,71 \\
\hline Porosidade total, \% & 62,00 & 46,00 & 54,25 & 3,52 & 6,50 & $-0,27$ & $-0,24$ & 68,35 & 40,15 \\
\hline Macroporosidade, \% & 32,00 & 9,00 & 21,36 & 5,20 & 24,37 & $-0,43$ & $-0,06$ & 42,19 & 0,53 \\
\hline \multirow[t]{2}{*}{ Microporosidade, \% } & 39,00 & 25,00 & 32,88 & 2,67 & 8,12 & $-0,09$ & 0,35 & 43,57 & 22,20 \\
\hline & & & & 2005 & & & & & \\
\hline Densidade, $\mathrm{kg} \mathrm{dm}^{-3}$ & 1,36 & 0,85 & 1,12 & 0,08 & 7,12 & 0,07 & 0,32 & 1,44 & 0,80 \\
\hline Porosidade total, \% & 75,77 & 41,26 & 59,54 & 4,39 & 7,38 & $-0,37$ & 2,22 & 77,13 & 41,95 \\
\hline Macroporosidade, \% & 34,94 & 8,08 & 19,52 & 4,81 & 24,64 & $-0,14$ & 1,85 & 38,02 & 1,19 \\
\hline Microporosidade, \% & 65,75 & 23,46 & 40,16 & 4,27 & 10,63 & 0,68 & 6,58 & 57,24 & 23,08 \\
\hline
\end{tabular}

$\mathrm{DP}=$ Desvio-padrão. CV = Coeficiente de Variação. 
Tabela 2. Parâmetros do semivariograma para os atributos físicos analisados em 1985 e 2005

\begin{tabular}{|c|c|c|c|c|c|}
\hline Atributo & Modelo & $\mathrm{C}_{0}$ & $\mathrm{C}_{1}$ & $\mathrm{a}$ & $\mathrm{RD}$ \\
\hline & & & & $(\mathrm{m})$ & $(\%)$ \\
\hline & & 1985 & & & \\
\hline Argila, $\mathrm{g} \mathrm{kg}^{-1}$ & Esférico & 4,12 & 5,79 & 110 & 41,57 \\
\hline Silte, $\mathrm{g} \mathrm{kg}^{-1}$ & Esférico & 1,90 & 1,9 & 85 & 50,00 \\
\hline Areia, $\mathrm{g} \mathrm{kg}^{-1}$ & Esférico & 6,00 & 8,1 & 60 & 42,55 \\
\hline Densidade, $\mathrm{kg} \mathrm{dm}^{-3}$ & \multicolumn{5}{|c|}{ Efeito pepita puro } \\
\hline Porosidade total, \% & \multicolumn{5}{|c|}{ Efeito pepita puro } \\
\hline Macroporosidade, \% & \multicolumn{5}{|c|}{ Efeito pepita puro } \\
\hline Microporosidade, \% & & & Efeito pepita puro & & \\
\hline \multicolumn{6}{|c|}{2005} \\
\hline Densidade, $\mathrm{kg} \mathrm{dm}^{-3}$ & Esférico & 0,005 & 0,001 & 65 & 21,93 \\
\hline Porosidade Total, \% & Esférico & 14,74 & 2,909 & 90,00 & 16,43 \\
\hline Macroporosidade, \% & Esférico & 21,70 & 2,700 & 70,00 & 11,06 \\
\hline Microporosidade, \% & Esférico & 10,90 & 3,400 & 42,00 & 23,77 \\
\hline
\end{tabular}

$\mathrm{C}_{0}=$ Efeito pepita; $\mathrm{C}_{1}=$ Variância estrutural; $\mathrm{a}=$ alcance; $\mathrm{RD}=$ Razão de dependência espacial.

Carvalho et al. (2001) descrevem que os valores elevados de efeito pepita $\left(C_{0}\right)$ indicam maior descontinuidade entre amostras. Os atributos texturais amostrados em 1985 representam os menores valores de $\mathrm{C}_{0}$ quando comparados com os demais atributos estudados, exceto a densidade em 2005 com valor de $\mathrm{C}_{0}$ de 0,005 .

Os valores de alcance (a) demonstram até que ponto as amostras são correlacionadas entre si, representando desta maneira, a distância máxima de dependência espacial entre amostras (VIEIRA, 2000). Observa-se que os atributos estudados possuem distintos valores de alcance, variando entre $42 \mathrm{~m}$ (microporosidade do solo em 2005) e 110 m (conteúdo de argila em 1985). Segundo, CARvalHo et al. (2003) o conhecimento do alcance da dependência espacial, permite o delineamento de futuras amostragens assegurando as mesmas condições do estudo em questão. Todavia, conforme já descrito anteriormente, o espaçamento de $20 \mathrm{~m}$ x $20 \mathrm{~m}$ não foi suficiente para detectar a variabilidade espacial entre amostras de alguns atributos físicos do solo (densidade, porosidade total, macroporosidade e microporosidade) no ano de 1985, indicando que o raio de variabilidade do alcance é inferior a esta distância. Por outra parte, para a amostragem realizada em $2005(10 \mathrm{~m} \times 10 \mathrm{~m})$ o raio de variabilidade do alcance ocorre aos $42 \mathrm{~m}$ (microporosidade) superando em quatro vezes a distância de amostragem (10 $\mathrm{m} \times 10 \mathrm{~m})$.

De acordo com CorÁ et al. (2004) e REICHARDT e Timm (2004), o manejo do solo altera a variabilidade natural do solo principalmente nas camadas superficiais. Desse modo, pode-se descrever que com o manejo do solo com semeadura direta ao longo dos anos na área de estudo foi alterada a variabilidade do solo, pois em 1985 em muitos dos atributos analisados não havia variabilidade espacial. Todavia, em 2005, a variabilidade espacial dos atributos foi detectada e, incluso com um raio mínimo de alcance da variabilidade espacial de 42 $\mathrm{m}$ (microporosidade), representando o dobro do espaçamento utilizado em 1985 (20 m x $20 \mathrm{~m}$ ), indicando melhoria da variabilidade espacial com o decorrer dos anos. CAMPos et al. (1995) e AMADO et al. (2005) descrevem que o sistema de semeadura direta representa maior estabilidade dos agregados e continuidade dos poros com o decorrer dos anos, resultado da melhoria estrutural do solo pelo aporte contínuo de matéria orgânica em superfície. Assim, pode-se dizer que a melhoria da qualidade estrutural da camada superficial do solo na área de estudo, favoreceu a variabilidade espacial dos atributos físicos do solo no período entre 1985 e 2005, uma vez que em 1985 a amostragem $(20 \mathrm{~m} \times 20 \mathrm{~m})$ não foi capaz de detectar a variabilidade espacial.

Os mapas de variabilidade espacial dos atributos texturais do solo amostrados em 1985 (argila, silte e areia) (Figura 2) demonstram que o maior conteúdo de argila na área em estudo está localizado na metade superior esquerda da área, enquanto os maiores conteúdos de areia estão presentes na parte inferior direita da área. 

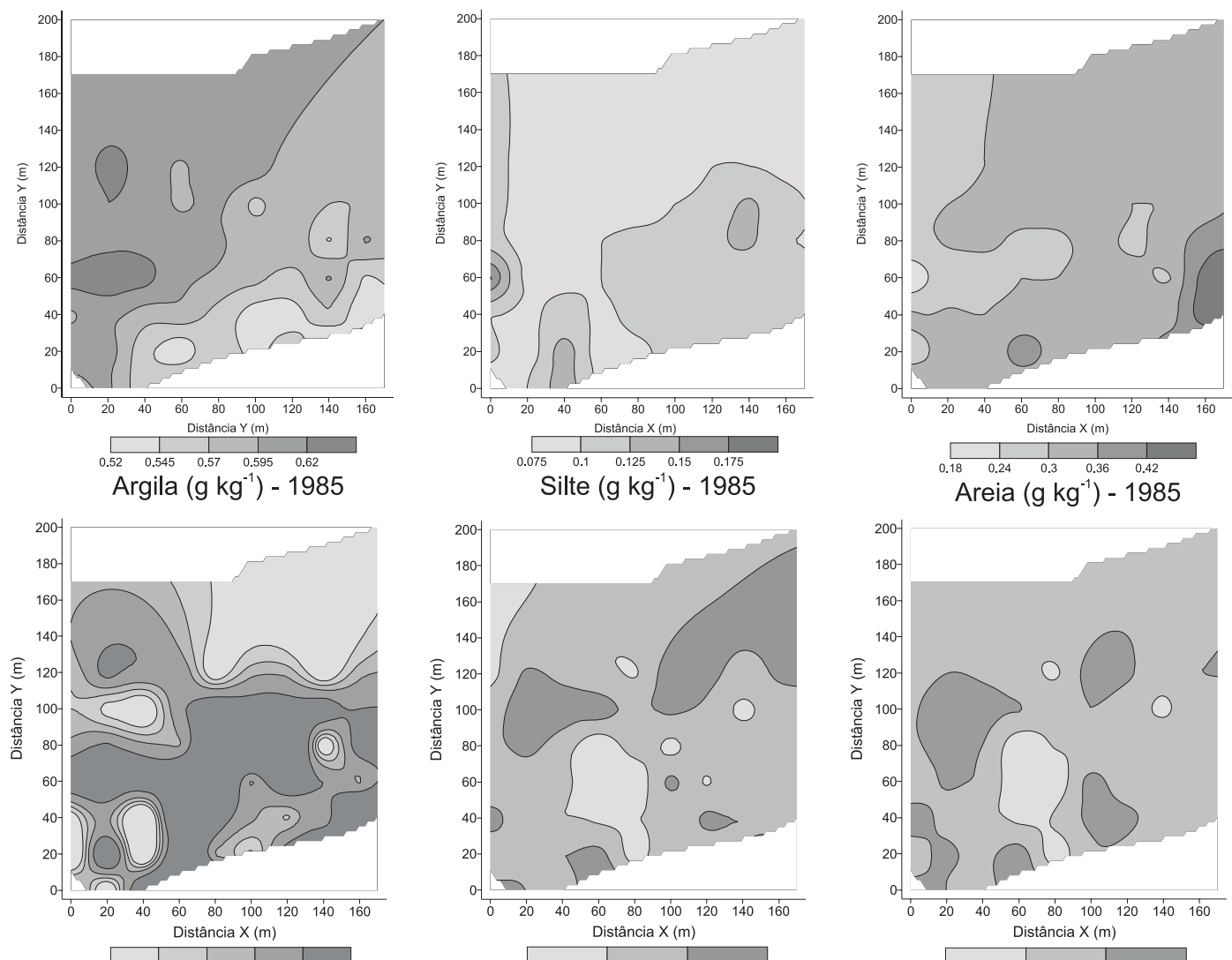

$\begin{array}{lllll}0.95 & 1.09 & 1.12 & 1.15 & 1.2\end{array}$

Densidade $\left(\mathrm{kg} \mathrm{dm}^{-3}\right)-1985$

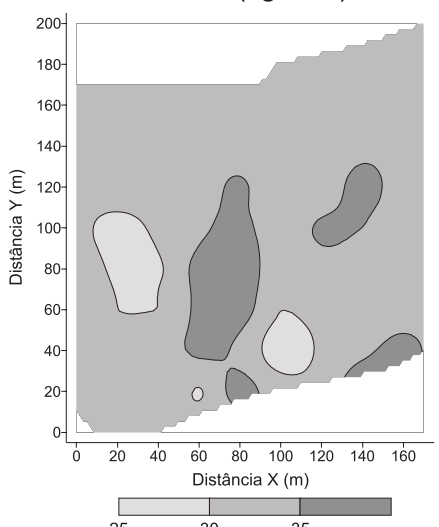

Porosidade Total (\%) - 1985

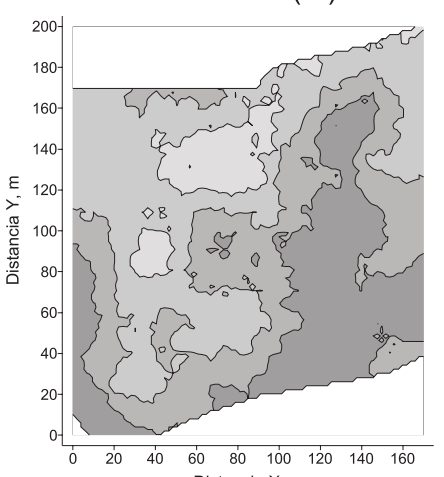
Distancia $\mathrm{X}, \mathrm{m}$

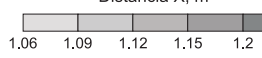

$\stackrel{25}{25}{ }^{30}{ }^{35}$ Microporosidade $(\%)-1985$

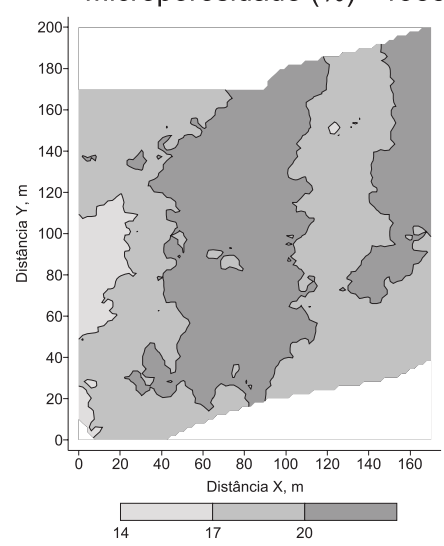

Densidade $\left(\mathrm{kg} \mathrm{dm}^{-3}\right)-2005$

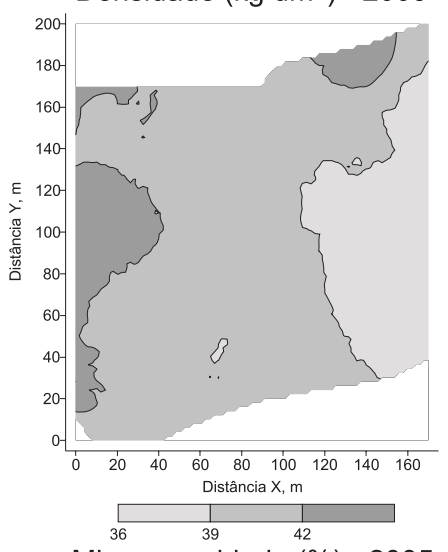

Macroporosidade (\%) - 1985

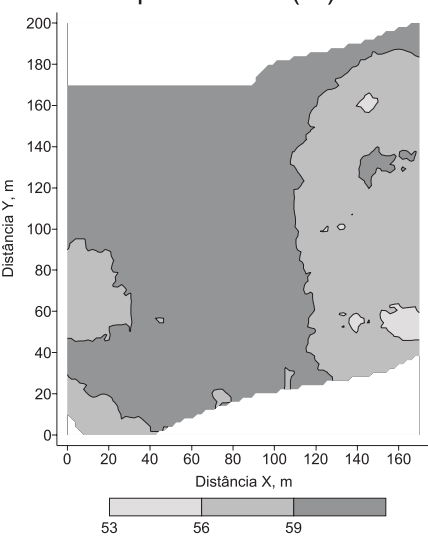

Porosidade Total (\%) - 2005

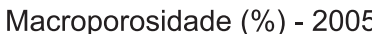

Microporosidade (\%) - 2005

Figura 2. Mapas de isolinhas para os atributos físicos do solo amostrados em 1985 e 2005. 
Stone e Silveira (2001) ressaltam que no sistema de semeadura direta os maiores problemas de compactação estão relacionados com as operações de manejo realizadas em solos argilosos com teores elevados de umidade. Assim, podem-se relacionar os mapas dos atributos texturais do solo com os demais atributos físicos estudados. Verifica-se que a densidade do solo em 1985 (Figura 2) localiza-se em zonas com densidade do solo maior que $1,2 \mathrm{~kg} \mathrm{dm}^{-3}$, coincidindo com as zonas com maiores conteúdos de argila $\left(>0,62 \mathrm{~g} \mathrm{~kg}^{-1}\right)$. No entanto, o mapa de densidade do solo em 2005 indica os maiores valores na parte inferior direita da área, não havendo uma relação clara entre o conteúdo de argila $\left(\mathrm{g} \mathrm{kg}^{-1}\right)$ e a densidade do solo $\left(\mathrm{kg} \mathrm{dm}^{-3}\right)$.

A porosidade total (\%) e a macroporosidade (\%) em 1985 revelam comportamento semelhante ao mapa de isolinhas da densidade do solo, onde as zonas com os maiores valores de densidade possuem os menores valores de porosidade total e de macroporosidade. A microporosidade do solo (\%, 1985) revela comportamento inverso ao da porosidade total e o da macroporosidade do solo.

As comparações entre os mapas de textura do solo em 1985 (argila, silte e areia) e os mapas da densidade e porosidade do solo, em 2005, demonstram que as zonas com maiores valores de densidade do solo em 2005 não são necessariamente as zonas com maior conteúdo de argila, havendo uma concentração da densidade do solo em 2005 na parte direita da área. A porosidade total $(\%, 2005)$ e a macroporosidade $(\%$, 2005) têm o mesmo padrão de distribuição das linhas de contorno que o mapa da densidade do solo. Por sua vez, a microporosidade em 2005 (\%) também possui distribuição das linhas de contorno inversa ao mapa de densidade, havendo maiores valores de microporosidade na parte lateral direita da área, aparentemente coincidindo com o conteúdo de argila do solo, uma vez que no mapa de microporosidade há pouca variação para a área de estudo.

Não há um consenso entre pesquisadores sobre um valor crítico de densidade do solo. De MARIA et al. (1999) e GuimarÃEs e Moreira (2001) descrevem que valores de densidade do solo acima de $1,2 \mathrm{~kg} \mathrm{dm}^{-}$ ${ }^{3}$ são restritivos para o desenvolvimento de raízes das plantas. ARSHAD et al. (1996) descrevem que valores de densidade superiores a $1,35 \mathrm{~kg} \mathrm{dm}^{-3}$ restringem o desenvolvimento radicular em solo argiloso. QUEIROZ Voltan et al. (2000), estudando o desenvolvimento radicular de plântulas de soja em Latossolo Roxo, descrevem que valores de até $1,50 \mathrm{~kg} \mathrm{dm}^{-3}$ não afetam o desenvolvimento dessas plantas. CAMARGO e AlLEONI (1997) consideram o valor crítico de $1,55 \mathrm{~kg} \mathrm{dm}^{-3} \mathrm{em}$ solos franco-argilosos a argilosos para o desenvolvimento das culturas, quando então é considerado como compactado. Os valores da densidade do solo para a área em estudo (Tabela 1) variaram entre $0,94 \mathrm{~kg} \mathrm{dm}^{-3}$ e 1,43 $\mathrm{kg} \mathrm{dm}^{-3}$ em $1985 \mathrm{e}$ entre $0,85 \mathrm{~kg} \mathrm{dm}^{-3}$ e $1,36 \mathrm{~kg} \mathrm{dm}^{-3}$ em 2005. A análise dos mapas de variabilidade espacial da densidade do solo (1985 e 2005) demonstra que na área de estudo não há problemas de compactação que restrinja o desenvolvimento radicular, de acordo com o valor de $1,55 \mathrm{~kg} \mathrm{dm}^{-3}$ proposto por CAMARgo e Alleoni (1997). Todavia, pode-se ressaltar que o manejo do solo favoreceu uma mudança no comportamento espacial da densidade do solo, pois, em 1985 os maiores valores de densidade do solo estavam concentrados na parte inferior da área e em 2005 os maiores valores estão presentes na zona lateral direita da área.

ARSHAD et al. (1996) descrevem que valores de macroporosidade menores que $15 \%$ restringem o movimento de água no perfil do solo, que por sua vez influenciam o desenvolvimento vegetativo das culturas. Verifica-se na tabela 1 que, em 1985, a macroporosidade do solo revelou valores entre $9 \%$ e $32 \%$ e em 2005 entre $8,08 \%$ e 34,94\%. Em 1985 e em 2005, nos mapas de variabilidade espacial (Figura 2) observa-se que em poucas zonas os valores de macroporosidade eram menores que 15\%. KIEHL (1979) descreve que um solo ideal deve possuir um mínimo de $66 \%$ de microporos. No entanto, nos mapas de variabilidade espacial de ambas as datas de amostragens, os valores de microporosidade para a área de estudo são menores que $66 \%$. A comparação entre os mapas de variabilidade espacial da microporosidade em 1985 e 2005 demonstra que a microporosidade do solo é maior para a amostragem realizada em 2005.

\section{CONCLUSÕES}

1. Pela amostragem de $20 \mathrm{~m} \times 20 \mathrm{~m}$ realizada em 1985 não é possível detectar a variabilidade espacial de alguns dos atributos físicos do solo estudados (densidade, porosidade total, macroporosidade e microporosidade), uma vez que, nestes atributos, ocorre efeito pepita puro, descrevendo que o espaçamento é maior que o alcance da variabilidade destes atributos.

2. Os atributos texturais do solo (argila, silte e areia) amostrados em 1985 com espaçamento de 20 m x 20 m possuem mediana razão de dependência espacial com alcance variando entre $60 \mathrm{~m}$ (areia) e 110 $\mathrm{m}$ (argila). Por outra parte, os atributos físicos analisados em 2005 com espaçamento de $10 \mathrm{~m} \times 10$ $\mathrm{m}$ apresentaram alta razão de dependência espacial com valores de alcance variando entre $42 \mathrm{~m}$ (microporosidade) e $90 \mathrm{~m}$ (porosidade total). 
3. Na área de estudo, após vinte anos de manejo sob o sistema de semeadura direta, não se observam valores críticos de densidade e porosidade do solo prejudiciais ao desenvolvimento das culturas.

4. O manejo do solo com semeadura direta na área de estudo influenciou favoravelmente a variabilidade espacial dos atributos físicos do solo estudados após vinte anos de manejo (2005).

\section{AGRADECIMENTOS}

Os autores agradecem à FUNDAG - Fundação de Apoio à Pesquisa Agrícola, pela bolsa de Mestrado e pelo financiamento parcial deste projeto. Agradecem também aos técnicos do Centro de Pesquisa e Desenvolvimento de Solos e Recursos Ambientais do IAC, pelo apoio durante a coleta de dados e análises laboratoriais.

\section{REFERÊNCIAS}

AMADO, T.J.C.; NICOLOSO, R.; MASTRÂNGELLO, L.;SANTI, A. \& LOVATO, T. A compactação pode comprometer os rendimentos de áreas sob semeadura direta. Semeadura Direta, v. 89, p. 34-42, 2005.

ARSHAD, M.A.; LOWER, B.; GROSSMAN, B. Physical tests for monitoring soil quality. In: DORAN, J.W.; JONES, A.J. (Ed.). Methods for assessing soil quality. Madison: Soil Science Society of America, 1996. p.123-141. (SSSA Special publication 49)

BERTOL, I.; BEUTLER, J.F.; LEITE, D.; BATISTELA, O. Propriedades físicas de um Cambissolo Húmico afetadas pelo tipo de manejo do solo. Scientia Agricola, v.58, p.555$560,2001$.

BERTOLANI, F.C.; VIEIRA, S.R. Variabilidade especial da taxa de infiltração de água e da espessura do horizonte A, em um Argissolo Vermelho-Amarelo, sob diferentes usos. Revista Brasileira de Ciência do Solo, v.25, p.987-995, 2001.

BEUTLER, A.N.; SILVA, M.L.N; CURI, N.; FERREIRA, M.M.; CRUZ, J.C.; PEREIRA FILHO, I.A. Resistência à penetração e permeabilidade de Latossolo Vermelho distrófico típico sob sistemas de manejo na região dos cerrados. Revista Brasileira de Ciência do Solo, v.25, p.167-177, 2001.

CAHN, M.D.; HUMMEL, J.W.; BROUER, B.H. Spatial analysis of fertility for sitespecific crop management. Soil Science Society of America Journal, v.58, p.1240-1248, 1994.

CAMARGO, O.A.; ALLEONI, L.R.F. Compactação do solo e o desenvolvimento das plantas. Piracicaba: ESALQ, 1997. 132p.

CAMARGO, O.A.; MONIZ, A.C; JORGE, J.A.; VALADARES, J.M.A.S. Métodos de análise química, mineralógica e física de solos do Instituto Agronômico de Campinas. Campinas: Instituto Agronômico, 1986, 94p. (Boletim técnico, 106)
CAMBARDELLA, C.A.; MOOMAN, T.B.; NOVAK, J.M.; PARKIN, T.B.; KARLEM,D.L.; TURVO, R.F. \& KONOPA, A.E. Field scale variability of soil properties in central Iowa soil. Soil Science of America Journal, v.47, p.1501-1511, 1994.

CAMPOS, B.C.; REINERT, D.J.; NICOLODI, R.; RUEDELL, J.; PETRERE, C. Estabilidade estrutural de um Latossolo Vermelho-Escuro distrófico após sete anos de rotação de culturas e sistemas de manejo do solo. Revista Brasileira de Ciência do Solo, v.19, p.121-126, 1995.

CARVALHO, J.R.P.; VIEIRA, S.R.; MARINHO, P.R.; DECHEN, S.C.F.; MARIA, I.C.; POTT, C.A.; DUFRANC, G. Avaliação da variabilidade espacial de parâmetros físicos do solo sob semeadura direta em São Paulo - Brasil. Campinas: EMBRAPA, 2001. p.1-4. (Comunicado Técnico)

CARVALHO, M.P.; TAKEDA, E.Y.; FREDDI, O.S. Variabilidade espacial de atributos de um solo sob videira em vitória Brasil (SP). Revista Brasileira de Ciência do Solo, v. 27, p. 695-703, 2003.

CORA, J.E.; ARAÚJO, A.V.; PEREIRA, G.T.; BERALDO, J.M.G. Variabilidade espacial de atributos do solo para adoção do sistema de agricultura de precisão na cultura de cana-de-açúcar. Revista Brasileira de Ciência do Solo, v.28, p.1013-1021, 2004.

DE MARIA, I.C.; CASTRO, O.M.; DIAS, H.S. Atributos físicos do solo e crescimento radicular de soja em Latossolo Roxo sob diferentes métodos de preparo do solo. Revista Brasileira de Ciência do Solo, v.23, p.703-709, 1999.

EMBRAPA. Centro Nacional de Pesquisa de Solos. Sistema brasileiro de classificação de solos. Brasília: Embrapa Produção de Informação; Rio de janeiro: Embrapa Solos, 1999. 412p.

FAO. Soil Map of the World. Revised Legend. Rome: FAO, 1994.

FOLONI, J.S.S.; CALONEGO, J.C.; LIMA, S.L. Efeito da compactação do solo no desenvolvimento aéreo e radicular de cultivares de milho. Pesquisa Agropecuária Brasileira, v.38, p.947-953, 2003.

GOMES, F.P. A estatística moderna na pesquisa agropecuária. Piracicaba: Potafós, 1984. 160p.

GREGO, C.R.; VIEIRA, S.R. Variabilidade especial de propriedades físicas do solo em uma parcela experimental, Revista Brasileira de Ciência do Solo, v.29, p.169-177, 2005.

GUIMARÃES, C.M.; MOREIRA, J.A.A. Compactação do solo na cultura do arroz de terras altas. Pesquisa Agropecuária Brasileira, v.36, p.703-707, 2001.

KIEHL, E.J. Manual de edafologia. São Paulo: Agronômica Ceres, 1979. 262p.

KLEPKER, D.; ANGHINONI, I. Características físicas e químicas do solo afetadas por métodos de preparo e modos de aplicação. Revista Brasileira de Ciência do Solo, Campinas, v. 19, n. 3, p. 395-401, 1995. 
ORTOLANI, A.A.; CAMARGO, M.B.P.; PEDRO JÜNIOR, M.J. Normais climatológicas dos postos meteorológicos do Instituto Agronômico. 1. Centro Experimental de Campinas. Campinas: Instituto Agronômico, 1995. 13p. (Boletim Técnico, 155)

QUEIROZ-VOLTAN, R.B.; NOGUEIRA, S.S.S.; MIRANDA, M.A.C. Aspectos da estrutura da raiz e do desenvolvimento de plantas de soja em solos compactados. Pesquisa Agropecuária Brasileira. v.35, n.5, p.929-938, 2000.

REICHARDT, K.; TIMM, L.C. Solo, planta e atmosfera: conceitos, processos e aplicações. Barueri: Manole, 2004. 478p.

SHIPITALO, M.J.; PROTZ, R. Comparison of morphology and porosity of a soil under conventional and zero-tillage. Canadian Journal of Soil Science, v.67, p.445-456, 1987.

SIQUEIRA, G.M.; VIEIRA, S.R.; CEDDIA, M.B. Variabilidade espacial de atributos físicos do solo determinados por métodos diversos. Bragantia, v.67, p.203-211, 2008.

SOUZA, L.S.; COCO, N.P.; VIEIRA, S.R. Variabilidade de propriedades físicas e químicas do solo em um pomar cítrico. Revista Brasileira de Ciência do Solo, v.21, p.367-372, 1997.

SOUZA, Z.M.; MARQUES JÚNIOR, J. \& PEREIRA, G.T. Variabilidade espacial de atributos do solo em diferentes formas do relevo sob cultivo de cana-de-açúcar. Revista Brasileira de Ciência do Solo, Viçosa, v.28, p.937-944, 2004.

SPERA, S.T.; SANTOS, H.P.; FONTANELI, R.S.; TOMM, G.O. Efeitos de sistemas de produção de grãos envolvendo pastagens sob semeadura direta nos atributos físicos de solo e na produtividade. Revista Brasileira de Ciência do Solo, Viçosa, v.28, p.533-542, 2004.

STONE, L. F.; SILVEIRA, P. M. Efeitos do sistema de preparo e da rotação de culturas na porosidade e densidade do solo. Revista Brasileira de Ciência do Solo, v.25, p.395-401, 2001.

SURFER for windows. Realese 7.0. Contouring and 3D surface mapping for scientist's engineers. User's guide. New York: Golden Software, 1999. 619p.

TRANGMAR, B.B.; YOST, R.S.; UEHARA, G. Application of geoestatistics to spatial studies of soil properties. Advances in Agronomy, v.38, p.45-93, 1985.

USDA - UNITEDSTATES DEPARTMENT OF AGRICULTURE. Keys to soil taxonomy. 7.ed. Washington: USDA, 1996. 644 p.

VIEIRA, S.R. Geoestatística em estudos de variabilidade espacial do solo. In: NOVAIS, R.F., ALVAREZ, V.H., SCHAEFER, G.R. (Ed.). Tópicos em Ciência do solo. Viçosa: Sociedade Brasileira de Ciência do Solo, v.1, 2000. p.1-54.

VIEIRA, S.R.; MILLETE, J.; TOPP, G.C.; REYNOLDS, W.R. Handbook for geostatistical analysis of variability in soil and climate data. In: ALVARES, V.H.; SCHAEFER, C.E.G.R.; BARROS, N.F.; MELLO, J.W.V.; COSTA, L.M. Tópicos em Ciência do Solo. Viçosa: UFV, 2002. v.2, p.1-46.
WARRICK, A.W.; NIELSEN, D.R. Spatial variability of soil physical properties in the field. In: HILLEL, D. Applications of soil physics. New York: Academic Press, 1980. p.319-344.

WEBSTER, R. Statistics to support soil research and their presentation. European Journal of Soil Science, v.52, p.331340, 2001. 